\title{
Chemical composition and radiative properties of nascent particulate matter emitted by an aircraft turbofan burning conventional and alternative fuels
}

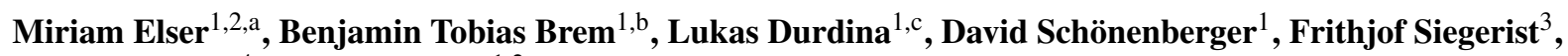 \\ Andrea Fischer ${ }^{4}$, and Jing Wang ${ }^{1,2}$ \\ ${ }^{1}$ Laboratory for Advanced Analytical Technologies, Empa, Dübendorf, 8600, Switzerland \\ ${ }^{2}$ Institute of Environmental Engineering, ETH, Zurich, 8093, Switzerland \\ ${ }^{3}$ SR Technics AG, Zurich Airport, 8058, Switzerland \\ ${ }^{4}$ Air pollution/Environmental Technology, Empa, Dübendorf, 8600, Switzerland \\ anow at: Automotive Powertrain Technologies Laboratory, Empa, Dübendorf, 8600, Switzerland \\ bnow at: Laboratory of Atmospheric Chemistry, Paul Scherrer Institute, Villigen, 5232, Switzerland \\ ${ }^{c}$ now at: Centre for Aviation, School of Engineering, Zurich University of Applied Sciences, Winterthur, 8401, Switzerland
}

Correspondence: Miriam Elser (miriam.elser@empa.ch)

Received: 5 November 2018 - Discussion started: 4 December 2018

Revised: 30 April 2019 - Accepted: 9 May 2019 - Published: 21 May 2019

\begin{abstract}
Aircraft engines are a unique source of carbonaceous aerosols in the upper troposphere. There, these particles can more efficiently interact with solar radiation than at ground. Due to the lack of measurement data, the radiative forcing from aircraft exhaust aerosol remains uncertain. To better estimate the global radiative effects of aircraft exhaust aerosol, its optical properties need to be comprehensively characterized. In this work we present the link between the chemical composition and the optical properties of the particulate matter (PM) measured at the engine exit plane of a CFM56-7B turbofan. The measurements covered a wide range of power settings (thrust), ranging from ground idle to take-off, using four different fuel blends of conventional Jet A-1 and hydro-processed ester and fatty acids (HEFA) biofuel. At the two measurement wavelengths (532 and $870 \mathrm{~nm}$ ) and for all tested fuels, the absorption and scattering coefficients increased with thrust, as did the PM mass. The analysis of elemental carbon (EC) and organic carbon (OC) revealed a significant mass fraction of OC (up to $90 \%$ ) at low thrust levels, while EC mass dominated at medium and high thrust. The use of HEFA blends induced a significant decrease in the PM mass and the optical coefficients at all thrust levels. The HEFA effect was highest at low thrust levels, where the EC mass was reduced by up to $50 \%-60 \%$. The variability in the chemical composition of the particles was the
\end{abstract}

main reason for the strong thrust dependency of the single scattering albedo (SSA), which followed the same trend as the fraction of OC to total carbon (TC). Mass absorption coefficients (MACs) were determined from the correlations between aerosol light absorption and $\mathrm{EC}$ mass concentration. The obtained MAC values $\left(\mathrm{MAC}_{532}=7.5 \pm 0.3 \mathrm{~m}^{2} \mathrm{~g}^{-1}\right.$ and $\mathrm{MAC}_{870}=5.2 \pm 0.9 \mathrm{~m}^{2} \mathrm{~g}^{-1}$ ) are in excellent agreement with previous literature values of absorption cross section for freshly generated soot. While the MAC values were found to be independent of the thrust level and fuel type, the mass scattering coefficients (MSCs) significantly varied with thrust. For cruise conditions we obtained $\mathrm{MSC}_{532}=$ $4.5 \pm 0.4 \mathrm{~m}^{2} \mathrm{~g}^{-1}$ and $\mathrm{MSC}_{870}=0.54 \pm 0.04 \mathrm{~m}^{2} \mathrm{~g}^{-1}$, which fall within the higher end of MSCs measured for fresh biomass smoke. However, the latter comparison is limited by the strong dependency of MSC on the particles' size, morphology and chemical composition. The use of the HEFA fuel blends significantly decreased PM emissions, but no changes were observed in terms of EC/OC composition and radiative properties. 


\section{Introduction}

The rapid rise of the aviation industry in the last decades and the continuous growth projected for the next 20 years (Leahy, 2016) have motivated the study of aircraft engine emissions and their related effects on the environment and human health. Several field and modelling studies have investigated the degradation of air quality near airports and have assessed the related effects on human health (e.g. Arunachalam et al., 2011; Barrett et al., 2013; Carslaw et al., 2006; Hsu et al., 2009; Lee et al., 2013; Schürmman et al., 2007, among others). Aircraft engines are also a unique source of gases and particles in the upper troposphere and lower stratosphere, where they alter the atmospheric composition and contribute to climate change. In a study on the impacts of emissions from commercial aircraft flights on climate, Jacobson et al. (2013) reported that aircraft emissions were responsible for $\sim 6 \%$ of the Arctic surface global warming and $\sim 1.3 \%$ of total surface global warming. The radiative forcing from aircraft emissions results from the direct release of radiatively active compounds (greenhouse gases and particulate matter (PM)), species that produce or destroy radiatively active substances (e.g. nitrogen oxides $\left(\mathrm{NO}_{x}\right)$ as an ozone precursor) and species that trigger the formation of condensation trails and cirrus clouds (Penner et al., 1999). Of special interest are the aerosol-light interactions by strongly absorbing black carbon (BC), which are known to cause positive radiative forcing (i.e. warming). Although aviation $\mathrm{BC}$ emissions are very small relative to other anthropogenic sources like road transport, industry or biomass burning (Balkanski et al., 2010; Hendricks et al., 2004; Karagulian et al., 2017), their radiative effects can be enhanced when emitted at high altitude and over high surface albedo such as snow and ice surfaces or clouds. In fact, several model studies have shown that the direct radiative forcing (DRF) of BC strongly increases with altitude (e.g. Samset and Myhre, 2011; Zarzycki and Bond, 2010) and that globally, more than $40 \%$ of the total DRF of BC is exerted at altitudes above $5 \mathrm{~km}$ (Samset et al., 2013). The presence of clouds is a major contributor to the altitude dependency of the DRF of BC, but other factors such as surface albedo, water vapour concentrations and background aerosol distributions also contribute (Haywood and Shine, 1997; Samset and Myhre, 2011; Zarzycki and Bond, 2010). A detailed understanding of the optical properties of the carbonaceous particles emitted from aircraft exhaust is therefore essential to estimate the related climate effects.

Atmospheric PM scatters and absorbs solar radiation. Commonly reported optical parameters of PM include the absorption and scattering coefficients $\left(b_{\mathrm{abs}}\right.$ and $b_{\text {scat }}$, respectively) and the single scattering albedo (SSA), defined as the ratio between light scattering and total extinction (absorption + scattering). The optical coefficients are often normalized to the particles' mass to provide the mass absorption and mass scattering coefficients (MAC and MSC, re- spectively), which are essential parameters in atmospheric radiative transfer models. The MAC, MSC and SSA are key optical properties for the assessment of the aerosol radiative effects and depend on the particle size, morphology and chemical composition. In the case of aircraft emissions, the characteristics of the PM emissions are influenced by the engine type, the thrust level (power) at which the engine is operated and the fuel properties. The lack of experimental data on the optical properties of aircraft PM emissions has led to the extended use of generalized soot properties as an approximation to model aircraft radiative effects. This can lead to large discrepancies in the results, as the soot characteristics that determine the optical properties significantly vary among different combustion sources and combustion conditions. For example, aircraft soot particles are characterized by a very high degree of crystallinity and low oxidative reactivity (Liati et al., 2014; Parent et al., 2016), which might affect light absorption properties. In their meticulous review work, Bond and Bergstrom (2007) suggested a consistent MAC for fresh light-absorbing carbon $\left(\mathrm{MAC}_{\lambda=550 \mathrm{~nm}}=7.5 \pm 1.2 \mathrm{~m}^{2} \mathrm{~g}^{-1}\right)$, independent of the combustion source or conditions. Higher MAC values were attributed to coating of the particles with negligibly absorbing carbon. While in the size range of particles emitted from combustion processes the MAC stays nearly constant, the MSC has a strong dependency on the particle size (Hand and Malm, 2007), relative humidity (Khalizov et al., 2009) and coating with non-absorbing carbon (He et al., 2015). Levin et al. (2010) measured MSCs at $532 \mathrm{~nm}$ in the range 1.5$5.7 \mathrm{~m}^{2} \mathrm{~g}^{-1}$ for fresh biomass burning smoke from a variety of fuels. In addition, a previous study of biomass burning emissions from Reid et al. (2005) reported a smaller range of MSC $\left(3.2-4.2 \mathrm{~m}^{2} \mathrm{~g}^{-1}\right)$ for fresh smoke, and larger MSC values for aged (coated) smoke $\left(3.5-4.6 \mathrm{~m}^{2} \mathrm{~g}^{-1}\right)$. Thus, while the MAC likely depends on the particles' chemical composition and morphology, the MSC (and SSA) also has a strong dependency on the particles' size. As indicated by our results, both the chemical composition and the particle size of aircraft fresh PM emissions largely vary with engine thrust. Therefore, the study of the thrust and fuel dependency of the radiative properties (MAC, MSC and SSA) of aircraft PM emissions is of key importance to decrease the uncertainty in the modelling of their radiative effects.

Concerns of the limited reserves of fossil fuels and the environmental impacts of their consumption have led to the introduction of aviation biofuels. Compared to the standard Jet A-1 fuel, biofuels can have lower net $\mathrm{CO}_{2}$ emissions on a life cycle basis. The ASTM D7566 (standard specification for aviation turbine fuel containing synthesized hydrocarbons) allows a maximum biofuel content of $50 \%$ in jet fuels and sets restrictions to the blend aromatic content (minimum of $8 \%$ ), lubricity, density, freezing point and viscosity (ASTM D7566-17a, 2017). One of the five ASTM-certified blending components is biofuel from hydro-processed esters and fatty acids (HEFA), which can be produced from any form of fat 
or oil (e.g. waste fats from food industry or vegetable oils and fatty acids from oil/fat refining processes). The main difference between HEFA fuel and conventional Jet A-1 fuel is the absence of sulfur and aromatic species, commonly present in Jet A-1 in the range of $10-1000 \mathrm{ppm}$ of sulfur and around $18 \%$ of aromatic content (Hadaller and Johnson, 2006). Previous works have shown that reducing sulfur and aromatics in the fuel decreases the sulfate and $\mathrm{BC}$ emissions, respectively (Penner et al., 1999; Beyersdorf et al., 2014; Moore et al., 2015; Brem et al., 2015; Lobo et al., 2016). Moreover, a recent study on in-flight cruise emissions from the NASA DC-8 turbofan engines (CFM56-2-C1) has shown that using a $50: 50$ blend of Jet A and a Camelina-based HEFA biofuel reduces the particle emissions by $50 \%-70 \%$ (Moore et al., 2017).

In this work we study the link between the chemical composition and the optical properties of the PM measured at the engine exit plane of a CFM56-7B turbofan for different engine loads and HEFA fuel blends. The measurements were performed using an in-service engine from the Boeing 737 Next Generation, which constitutes around $30 \%$ of all commercial airliners, and is therefore representative of the current fleet. The chemical characterization of the exhaust was based on the quantification of elemental and organic carbon (EC/OC analysis) from filter samples, while the optical properties were measured online at two different wavelengths. The resulting optical properties were then integrated in a simple two-stream radiative model to estimate the direct forcing of fresh particle emissions from aircraft turbines during cruise conditions. The simple forcing efficiency (SFE; Chylek and Wong, 1995) was evaluated over the entire solar spectrum for various surface albedos, including sea, grass, soil and snow. Complex models are required to model the atmospheric ageing of the particles in the plume and to assess the radiative effects of the aged particles, which might significantly differ from those of the fresh emissions reported here.

\section{Methods}

\subsection{Experimental set-up}

The measurements were performed at the engine test cell of SR Technics at Zurich Airport (Switzerland) using an inservice commercial turbofan CFM56-7B burning four different blends of Jet A-1 and HEFA fuel (HEFA vol. percentage of $0 \%, 5 \%, 10 \%$ and $32 \%$ ). A schematic of the experimental set-up is shown in Fig. 1. The exhaust was sampled at the engine exit plane using a single-point sampling probe and then split into three sampling lines: the PM line for measurements of the particulate fraction, the GenTox line for the sampling of genotoxic compounds and the Annex 16 line for the measurements of the gaseous emissions and smoke number. The PM line was diluted with dry synthetic air (dilution factor $\sim 10$ ) to prevent water condensation and coagulation of the particles in the sampling line. The nonvolatile PM (nvPM) measurement system is compliant with the new ICAO standard (ICAO, 2017). The instruments relevant for this work are shown in blue in Fig. 1. The chemical composition was determined from the analysis of filter samples with a Sunset OC-EC Aerosol Analyzer (Sunset Laboratory Thermal/Optical Carbon Analyzer, Model 4L). The optical properties were monitored online with a PhotoAcoustic Extinctiometer (PAX; Droplet Measurement Technologies, $\lambda=870 \mathrm{~nm}$ ) and a Cavity Attenuated Phase Shift PM single scattering albedo monitor (CAPS PM SSA $_{\text {; Aero- }}$ dyne, $\lambda=532 \mathrm{~nm}$ ). The particle size distribution was measured using a Scanning Mobility Particle Sizer (SMPS; TSI, Model 3938). The BC mass concentration was measured using a Micro-Soot Sensor (MSS; AVL, Model 483). The $\mathrm{NO}_{2}$ measurement (Eco Physics, CLD844 S hr) was used to perform an online correction of the interference in the optical measurements at $532 \mathrm{~nm}$. The $\mathrm{CO}_{2}$ analysers (Thermo Fisher Scientific Model 410i in the PM line and Horiba PG-250 in the Annex 16 line) were used to calculate the dilution factors. Additional details of the measurement set-up are provided in the Supplement (Sect. S1.1).

\subsection{Filter samples for EC/OC analysis}

Filter samples for EC/OC analysis were collected in the PM sampling line with a dual step stainless steel filter holder (URG, Series 2000-30FVT). Quartz fiber filters (Pall Tissuequartz, 2500QAT-UP) were used in both stages to collect the PM mass (main filter) and to determine the positive sampling artifact (back-up filter) from gaseous $\mathrm{OC}$ adsorbing onto the filter surface (Kirchstetter et al., 2001; Subramanian et al., 2004). Prior to sampling, the filters were baked for at least $6 \mathrm{~h}$ at $650^{\circ} \mathrm{C}$ to remove possible contamination of adsorbed carbon. The sampling flow was $5 \mathrm{~L} \mathrm{~min}^{-1}$, and the duration was adjusted to provide optimal mass surface loadings for the EC/OC analyses (around $7 \mu \mathrm{g} \mathrm{cm}^{-2}$ ). Stainless steel masks were deployed to reduce the sampling area of the filters and, as a result, increase the mass loading per sample area when needed. Overall, 16 sets of filters were collected to cover the full range of thrust levels for the Jet A-1 fuel and the $32 \%$ vol HEFA blend. The larger filter masks ( $24 \mathrm{~mm}$ inner diameter) were used to sample at high thrust levels (100\%$65 \%$ ), while the smaller masks ( $16 \mathrm{~mm}$ inner diameter) were required for the low thrust levels $(50 \%-7 \%)$.

The thermo-optical analysis for the quantification of EC and OC was performed using a Sunset OC-EC Aerosol Analyzer (Sunset Laboratory Thermal/Optical Carbon Analyzer, Model 4L). A detailed description of the method is reported in the Supplement Sect. S1.2. For the analysis, a modified NIOSH 5040 thermal protocol, summarized in Table S1 (Birch and Cary, 1996), with a transmittance optical correction for pyrolysis was used. 


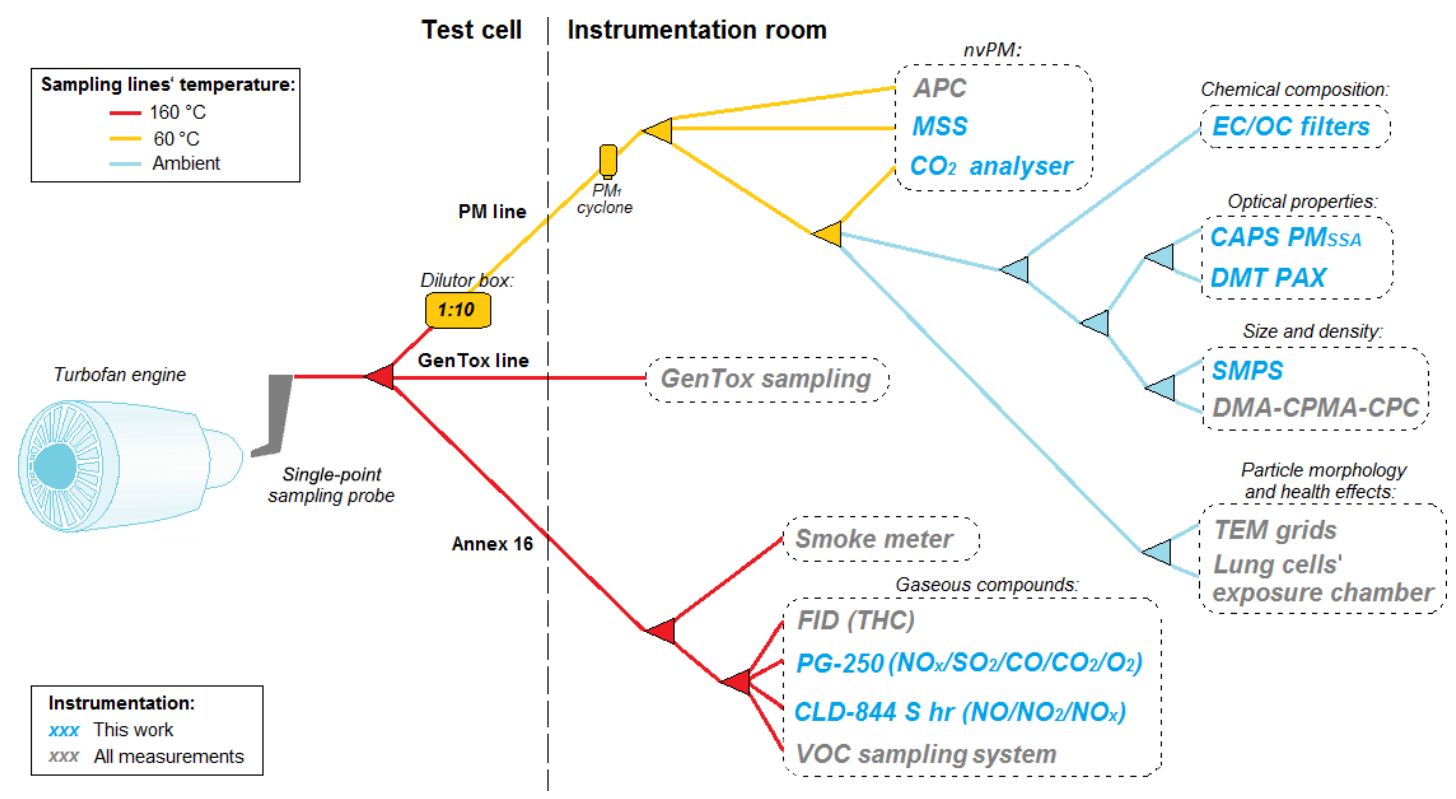

Figure 1. Experimental set-up during EMPAIREX 1. Instruments depicted in blue were used in this work, which included a Micro Soot Sensor (MSS), a Cavity Attenuated Phase-Shift Single Scattering Monitor (CAPS PMSSA), a Photo Acoustic Extinctiometer (DMT PAX), a Scanning Mobility Particle Sizer (SMPS), a $\mathrm{CO}_{2}$ analyser, a Portable Multi Gas Analyzer (PG-250) and a Chemiluminescence Detector (CLD-844). Additional instrumentation that was not used in this work (depicted in grey) is described in the Supplement (Sect. S1.1).

\subsection{Measurement of the optical properties}

The DMT PAX monitor simultaneously measures the aerosol optical absorption and scattering using a modulated diode laser $(\lambda=870 \mathrm{~nm})$. The light absorption is determined using the photo-acoustic technique. The modulated laser beam heats up the absorbing particles, which quickly transfer the heat to the surrounding air, generating a pressure wave that is measured with a sensitive microphone. The light scattering of the bulk aerosol is measured with a wide-angle integrating reciprocal nephelometer. Since there is relatively little absorption from gases and non-BC aerosol species at the $870 \mathrm{~nm}$ wavelength, the absorption measurement corresponds to the BC mass. Therefore, using an appropriate mass absorption cross section (MAC), the PAX absorption measurement can be used to determine $\mathrm{BC}$ mass $\left(\mathrm{BC}_{\mathrm{PAX}}\right)$. Vice versa, comparing the absorption measurement with the $\mathrm{EC}$ mass from filter measurements, we can infer the $\mathrm{MAC}_{870}$ for aircraft engine exhaust.

The CAPS PMSSA monitor provides simultaneous measurement of aerosol light extinction and scattering (Onasch et al., 2015). The extinction measurement is based on the cavity attenuated phase shift technique, which evaluates the phase shift of a LED light $(532 \mathrm{~nm})$ in a very long optical path (up to $2 \mathrm{~km}$ ), created with very high reflectivity mirrors in the sampling cell $(30 \mathrm{~cm})$. In addition, the CAPS PMSSA includes an integrating sphere (integrated nephelometer) within the optical path for the measurement of particle scattering. A particle size-dependent truncation correction is required to take into account the light lost at extreme forward and backward scattering angles due to the apertures of the optical beam.

Laboratory calibrations of both instruments were performed prior to the measurement campaign using sizeselected ammonium sulfate and nigrosine PM (see Sect. S1.3 in the Supplement). In addition to the standard calibrations, corrections for the CAPS scattering signal outside the instrument linear range and for the interference from gaseous $\mathrm{NO}_{2}$ at the measurement wavelength were also developed (Figs. S2 and S3). While the measured $\mathrm{NO}_{2}$ interference in the CAPS extinction is fairly consistent with previously reported values, we also found an unexpected non-linear interference in the CAPS scattering signal. This was initially attributed to a possible light leak in the instrument, but the scattering interference persisted after the light sealing of the instrument was renewed. To further investigate this issue, we compared laboratory calibration data of both optical instruments with results from Mie theory (Figs. S4-S6). Although there are several assumptions within the Mie model that may not be totally satisfied by the laboratory-generated calibration particles (e.g. spherical and homogeneous particles), the agreement with the PAX absorption and scattering measurements is fairly good for both ammonium sulfate and nigrosine. In contrast, the CAPS measurements only agree well with Mie theory for purely scattering particles, i.e. ammonium sulfate. In the case of nigrosine, the CAPS measurements agree with Mie theory in terms of total extinction, but the measured scattering is around $43 \%$ higher than esti- 
mated from the model. Despite several experimental efforts, we could not find the origin of the discrepancies in the CAPS scattering measurement or a way to properly correct it. Instead, we derived the CAPS scattering coefficient from the PAX absorption measurement using a thrust-dependent absorption Ångström exponent (AAE) obtained from aircraft engine measurements with a seven-wavelength aethalometer. All the details of this calculation can be found in Sect. S1.5 in the Supplement.

\subsection{Fuel specifications}

The main differences between the conventional Jet A-1 fuel and the different HEFA blends used in this work are reported in Table 1. Most fuel properties were measured following the standard ASTM (American Society for Testing and Materials) methods, including the concentration of total aromatics, naphthalene and sulfur, the smoke point and the fuel density. In addition, the hydrogen mass concentration was determined by nuclear magnetic resonance, using a method equivalent to ASTM D7171. As expected, increasing the concentration of HEFA fuel in the blend corresponded to a reduction in the concentrations of the aromatic compounds (including naphthalene) and sulfur. In addition, with the addition of the HEFA fuel the hydrogen mass concentration and the smoke point increased, while the fuel density slightly decreased.

\subsection{Radiative properties}

The SSA, MAC and MSC were calculated for the two measurement wavelengths $(\lambda=532$ and $870 \mathrm{~nm})$ using the following relationships:

$$
\begin{aligned}
\operatorname{SSA}_{\lambda} & =\frac{b_{\text {scat }, \lambda}}{b_{\text {ext }, \lambda}} \\
\operatorname{MAC}_{\lambda} & =\frac{b_{\text {abs }, \lambda}}{\mathrm{EC}} \\
\operatorname{MSC}_{\lambda} & =\frac{\operatorname{SSA}_{\lambda} \cdot \mathrm{MAC}_{\lambda}}{1-\operatorname{SSA}_{\lambda}} .
\end{aligned}
$$

In addition, to estimate the instantaneous direct radiative effects of the PM from fresh aircraft engine exhaust, we evaluated the radiative transfer equation introduced by Chylek and Wong (1995), modified as in Bond et al. (2007), to express the wavelength-dependent SFE in terms of the MSC and the MAC:

$$
\begin{aligned}
& \boldsymbol{S F E}(\boldsymbol{\lambda})=-\frac{\boldsymbol{S}_{0}(\boldsymbol{\lambda})}{4} \boldsymbol{T}_{\mathrm{atm}}^{2}(\lambda, z)\left(1-F_{\mathrm{c}}\right) \\
& \quad\left[2\left(1-\boldsymbol{a}_{\mathrm{s}}(\lambda)\right)^{2} \beta \boldsymbol{M S C}(\boldsymbol{\lambda})-4 a_{\mathrm{s}}(\lambda) \boldsymbol{M A C}(\boldsymbol{\lambda})\right],
\end{aligned}
$$

where $\boldsymbol{S}_{0}$ is the top of the atmosphere solar irradiance, $\boldsymbol{T}_{\mathrm{atm}}$ is the atmospheric transmission, $F_{\mathrm{c}}$ is the cloud fraction, $\boldsymbol{a}_{\mathrm{s}}$ is the surface albedo, $\beta$ is the backscatter fraction, $\lambda$ is the wavelength and $z$ is the height over sea level.
The MAC and MSC determined for the two measurement wavelengths were fitted over the entire range of the solar radiation spectrum $(280-4000 \mathrm{~nm})$ using the power law relationships:

$\operatorname{MAC}(\lambda)=a \lambda^{-\mathrm{AAE}}$
$\operatorname{MSC}(\lambda)=b \lambda^{-\mathrm{SAE}}$,

where $a$ and $b$ are fitting parameters, and AAE and SAE represent the absorption and scattering Ångström exponents, respectively. The selection of the parameters in Eqs. (4) to (6) is discussed in Sect. S2.4.

\section{Results and discussion}

All the results presented in this work were corrected to the engine exit plane, taking into account the dilution in the PM line and the particle losses in the sampling system. The $\mathrm{CO}_{2}$ measurements in the Annex 16 and the PM sampling lines were used to determine the dilution factor, and a correction was developed to estimate the thermophoretic losses and the size-dependent diffusion losses in the various sampling lines. Some additional considerations are needed regarding the representativeness of the data presented in this work. First, our results characterize the emissions at the engine exit plane from an engine operated at the ground. Thus, a correction to take into account the atmospheric conditions (temperature and pressure) at flight altitude is in principle necessary. However, as shown in Durdina et al. (2017), using data from a turbofan engine representative of modern commercial engines (Howard et al., 1996), the altitude does not significantly influence the PM size distributions. While ambient conditions will affect the plume evolution, the effect on the PM chemistry at the engine exit plane can be assumed to be minimal. Consequently, also the optical properties, which strongly depend on the particle size and chemical composition, would remain unvaried at the engine exit plane. Hence we assume the altitude correction for the optical properties at the engine exit plane to be negligible. It is important to note, however, that most gaseous and particle species measured at the engine exit plane will rapidly evolve in the atmosphere, and their radiative effects can largely vary from those of the direct emissions presented in this work, in which the collected data correspond to a time after emission of approximately 0.1 to $0.6 \mathrm{~s}$ (Brem et al., 2015). Additional measurements are therefore required in order to assess the evolution of the particles' optical properties in the emission plume. In any case, the emissions at the engine exit plane are the basis to consider the evolution of PM properties and are therefore the baseline for diverse atmospheric modelling scenarios.

\subsection{Chemical composition}

An overview of the main findings from the EC/OC analysis is presented in Figs. 2 and 3. The OC concentrations 
Table 1. Fuel specifications overview (NA: measurement not available).

\begin{tabular}{llrrrr}
\hline Property (units) & Method & Jet A-1 & HEFA 5\% & HEFA 10\% & HEFA 32\% \\
\hline Aromatics $(\% v / v)$ & ASTM D 1319 & 18.1 & 17.1 & 16.2 & 11.3 \\
Naphthalenes (\% $v / v$ ) & ASTM D 1840 & 0.79 & NA & NA & 0.53 \\
Sulfur (ppm) & ASTM D 5453 & 490 & NA & NA & 350 \\
Hydrogen mass $(\% \mathrm{~m} / \mathrm{m}$ ) & NMR & 13.61 & 13.68 & 13.75 & 14.09 \\
Smoke point (mm) & ASTM D 1322 & 22 & NA & NA & 24 \\
Density $\left(\mathrm{kg} \mathrm{m}^{-3}\right)$ & ASTM D 4052 & 794.8 & 793.3 & 791.2 & 781.8 \\
\hline
\end{tabular}

were corrected to take into account the positive sampling artifact as described in the Supplement (Sect. S2.1). The EC, OC and total carbon (TC) mass concentrations are reported in Table S3. Additionally, in Table S4 we also report the mass emission index of $\mathrm{EC}\left(\mathrm{EI}_{\mathrm{m}, \mathrm{EC}}\right.$, in $\left.\mathrm{mg} \mathrm{kg}_{\text {fuel }}^{-1}\right)$, together with the additional parameters required for the calculation of EIs (i.e. carbon dioxide, carbon monoxide and hydrocarbon concentrations) and the particles' size parameters (geometric mean diameter, GMD, and geometric standard deviation, GSD). Representative thermograms illustrating the EC/OC split for samples at low, medium and high thrust levels are reported in Fig. S9.

Figure 2 displays the mass concentrations of EC, OC and TC as a function of engine thrust and the concentration changes associated with the use of the $32 \%$ HEFA blend in comparison to the base Jet A- 1 fuel. For the Jet A-1 fuel, the concentrations of all three carbonaceous components increased with engine thrust, from a minimum of $0.1 \mathrm{mgTC} \mathrm{m}^{-3}$ at taxi $(\sim 6 \%$ thrust $)$ to a maximum of $5.6 \mathrm{mgTC} \mathrm{m}^{-3}$ at take-off ( $\sim 95 \%$ thrust). As the mass concentration increased with thrust, the GMD increased from $8 \mathrm{~nm}$ at taxi to $40 \mathrm{~nm}$ at take-off (Fig. S10). The slight increase in the mass concentrations between taxi and ground idle ( $\sim 3 \%$ thrust) has been observed in previous works (Durdina et al., 2017) and is associated with a decrease in the combustion efficiency and the air / fuel ratio. As illustrated by the bar plots, the use of the $32 \%$ HEFA blend induced a clear reduction in the EC concentrations at all thrust levels, in line with previous findings (Moore et al., 2015, 2017; Schripp et al., 2018). The HEFA effect was strongest at low thrust levels, inducing a decrease in EC mass of 50\%-60\% for thrust levels up to $30 \%$. An explanation for this thrust dependence can be found in Brem et al. (2015). However, very large uncertainties were associated with the EC measurements at ground idle due to low filter loading (down to $0.2 \mu \mathrm{g} \mathrm{cm}{ }^{-2}$ despite the long sampling times and the use of the small filter mask). For thrust levels of $50 \%$ and above, the decrease in EC mass with the HEFA blend became less significant, reaching a minimum EC decrease of $14 \%$ at take-off. A similar trend was observed for the $\mathrm{OC}$ and $\mathrm{TC}$ concentrations at high thrust levels. In contrast, the $\mathrm{OC}$, and consequently also the TC, seemed to be enhanced by the HEFA blend at ground idle.
Figure 3 shows the correlations of $\mathrm{EC}$ and $\mathrm{OC}$ with the $\mathrm{BC}$ mass concentrations measured with the MSS BC $_{\mathrm{MSS}}$, reported as nvPM mass in regulatory measurements of aircraft engine emissions). $\mathrm{EC}$ and $\mathrm{BC}_{\mathrm{MSS}}$ were in excellent agreement for both fuel types, with a slope very close to unity $(0.96 \pm 0.02)$ and Pearson's coefficient $\left(R^{2}\right)$ of 0.99 . Although $\mathrm{OC}$ also increased with $\mathrm{BC}_{\mathrm{MSS}}$, the correlation was weaker in this case, and small differences could be observed between the two fuels.

\subsection{Optical properties}

The main results from the measurement of the optical properties are reported in Figs. 4 and 5. For clarity, only the measurements with Jet A-1 fuel and the 32\% HEFA blend are shown, while the results from the intermediate HEFA blends (5\% and $10 \%$ ) are included in Fig. S11.

Figure 4 presents the thrust dependencies of the absorption, scattering and extinction coefficients, measured at $532 \mathrm{~nm}$ (CAPS, green squares) and $870 \mathrm{~nm}$ (PAX, blue circles). At both wavelengths, $b_{\mathrm{abs}}, b_{\mathrm{scat}}$ and $b_{\mathrm{ext}}$ showed similar thrust dependencies to those observed for EC, characterized by a large and continuous increase for thrust levels above $40 \%$. In addition, the use of the $32 \%$ HEFA blend induced a decrease in the three optical coefficients at most thrust levels.

Figure 5 shows the correlation between $b_{\mathrm{abs}}$ at the two measurement wavelengths and the EC mass concentration determined from the thermo-optical measurements. From the linear regressions we derived the MAC values for aircraft exhaust at 532 and $870 \mathrm{~nm}$, which appear to be independent of the particle size distribution, thrust or fuel type and will be further discussed in Sect. 3.4. The MAC 870 was used to calculate $\mathrm{BC}$ mass from the PAX absorption measurement $\left(\mathrm{BC}_{\mathrm{PAX}}\right)$, which was strongly correlated with $\mathrm{BC}_{\mathrm{MSS}}$ (Fig. S12, $R^{2}=0.99$, slope 0.98 ) and showed thrustdependent reductions with the HEFA blends (Fig. S13), consistent with the reductions in EC mass.

\subsection{Link between chemical composition and optical properties}

To investigate the link between the chemical composition and the optical properties of the aircraft emissions, in Fig. 6 we compare the thrust dependencies of the OC/TC fraction and 
(a)

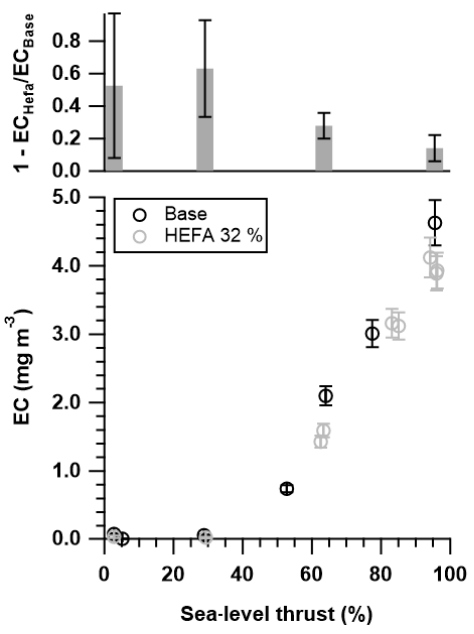

(b)
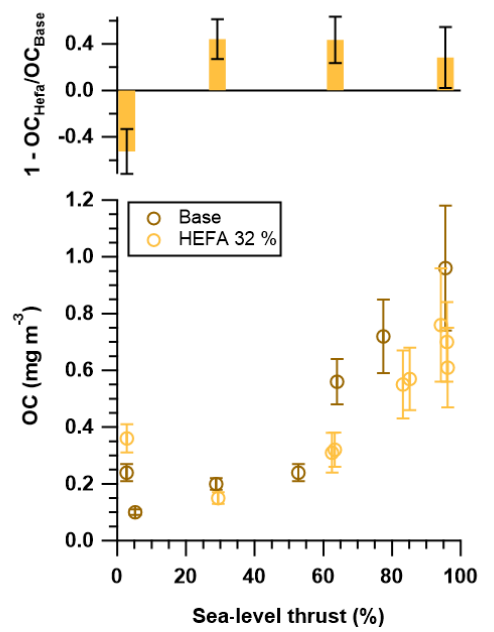

(c)

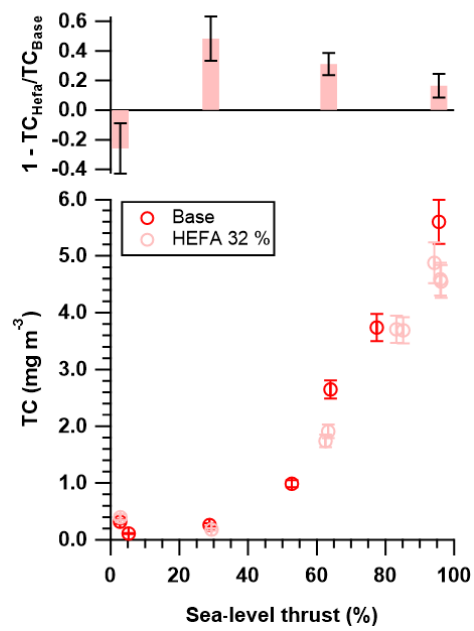

Figure 2. Thrust-dependent mass concentration and decrease with the $32 \%$ HEFA blend compared to the base Jet A-1 fuel of (a) elemental carbon (EC), (b) organic carbon (OC) and (c) total carbon (TC). Note that dark colours represent measurements with base fuel (Jet A-1), and light colours represent measurements with the HEFA blend ( $32 \%$ vol).
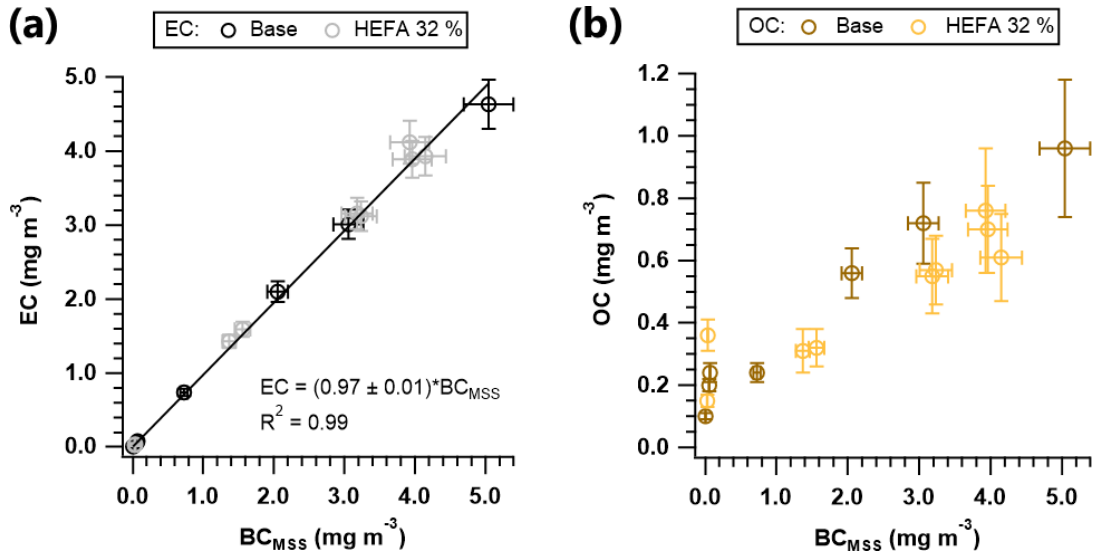

Figure 3. (a) Scatter plot and linear regression line of the mass concentrations of elemental carbon (EC) and black carbon measured with the micro soot sensor ( $\mathrm{BC}_{\mathrm{MSS}}$ ). (b) Scatter plot of the mass concentrations of organic carbon $(\mathrm{OC})$ and $\mathrm{BC}_{\mathrm{MSS}}$. Note that dark colours represent measurements with base fuel (Jet A-1), and light colours represent measurements with the HEFA blend (32\% vol).

the SSA, calculated at the two measurement wavelengths using Eq. (1). The OC/TC fraction showed a large variability with the thrust level, with OC/TC between 0.75 and 0.90 at low thrust levels $(3 \%-30 \%)$, decreasing to 0.25 at $50 \%$ thrust and down to 0.17 at take-off. Similar trends in the $\mathrm{OC} / \mathrm{TC}$ ratio with engine thrust have been observed in previous works (Delhaye et al., 2017). Although the use of the HEFA fuel had a strong effect on the EC and OC mass concentrations, it did not have any visible effect on the OC/TC fraction. The high OC content of the particles at low thrust levels resulted in very high SSA, which showed a maximum at ground idle $\left(\mathrm{SSA}_{532, \text { base }}=0.88\right.$ and $\left.\mathrm{SSA}_{870 \text {, base }}=0.55\right)$. Such high SSA values are common for particle emissions from biomass burning at low combustion efficiency (e.g. SSA $_{532} \sim 0.95$ in wildfire emissions; Liu et al., 2014). The
SSA decreased sharply between $30 \%$ and $60 \%$ thrust, likely due to the decreasing $\mathrm{OC}$ fraction, reaching a minimum at the combustor inlet temperatures and air/fuel ratios representative of cruise thrust $(\sim 60 \%$ thrust $)$, where $\mathrm{SSA}_{532 \text {, base }}=$ 0.29 and $\mathrm{SSA}_{870, \text { base }}=0.07$. These low SSA values are characteristic of primary on-road vehicle particle emissions (e.g. $0.22<\mathrm{SSA}_{675}<0.36$ from tunnel measurements; Strawa et al., 2010). Above $60 \%$ thrust we observed a slight increase in the SSA, which might be related to the increasing mean particle size (as the OC content remained constant in this thrust range). While there was no visible effect of the HEFA blend at the high thrust levels, it seems that slightly higher SSA were associated with the HEFA blend at low thrust levels.

The similarities observed in the thrust dependencies of the $\mathrm{OC} / \mathrm{TC}$ and the SSA, as well as the high correlation between 
(a)

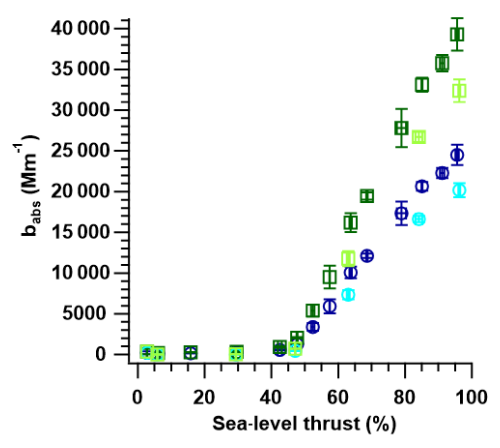

(b)

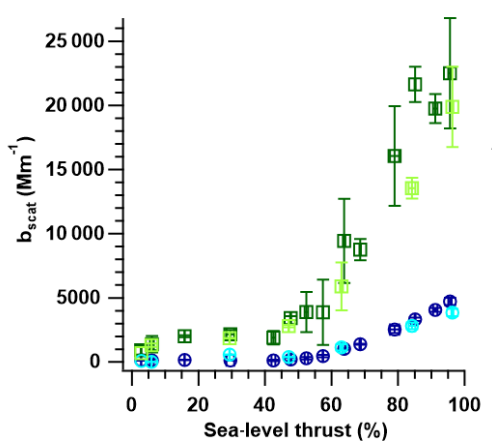

(c)

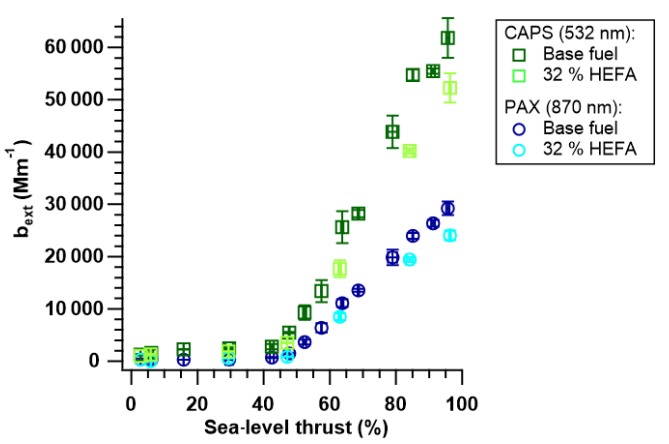

Figure 4. Thrust-dependent (a) absorption coefficient $\left(b_{\text {abs }}\right)$, (b) scattering coefficient $\left(b_{\text {scat }}\right)$ and $(\mathbf{c})$ extinction coefficient $\left(b_{\text {ext }}\right)$ measured at $532 \mathrm{~nm}$ (green squares) and $870 \mathrm{~nm}$ (blue circles). Note that dark colours represent measurements with base fuel (Jet A-1), and light colours represent measurements with the $32 \%$ vol HEFA blend.

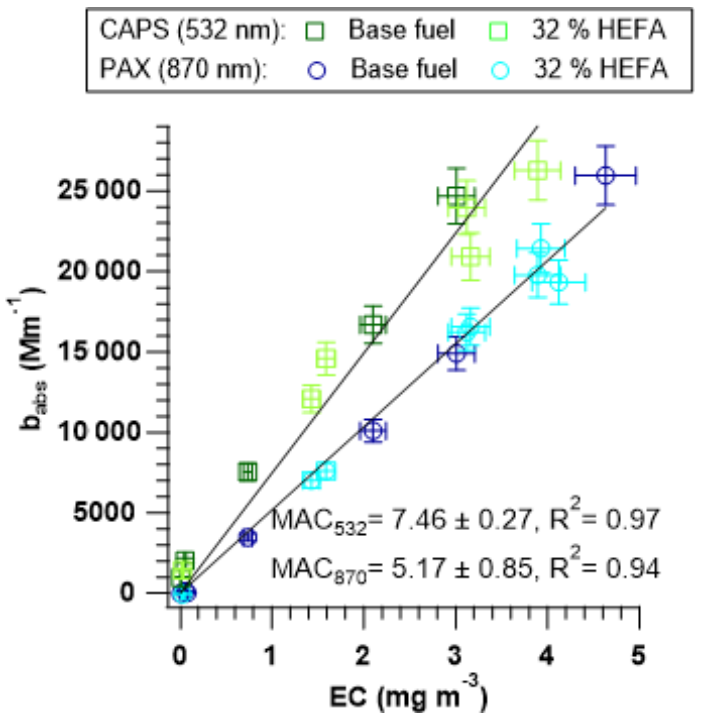

Figure 5. Scatter plot and linear regression lines between the absorption coefficient $\left(b_{\text {abs }}\right)$ measured at $532 \mathrm{~nm}$ (green squares) and $870 \mathrm{~nm}$ (blue circles) and the elemental carbon (EC) mass concentration. Mass absorption cross section (MAC) values are retrieved from the slope of the linear fits. Note that dark colours represent measurements with base fuel (Jet A-1), and light colours represent measurements with the HEFA blend (32\% vol).

$\mathrm{BC}_{\mathrm{PAX}}, \mathrm{BC}_{\mathrm{MSS}}$ and $\mathrm{EC}$, indicate that the $\mathrm{OC}$ content in these particles strongly enhanced light scattering at both measurement wavelengths but did not have a substantial effect on the light absorption. The increased OC content of the PM with decreasing engine power is in agreement with the observations of Vander Wal et al. (2016) and could be explained by inefficient and incomplete combustion at the lower thrust levels. The thermograms from the EC/OC analysis show a large OC volatility range for all thrust levels, with a major fraction of OC evaporating between 200 and $310^{\circ} \mathrm{C}$, especially at low thrust (Fig. S9).

\subsection{Radiative properties}

The MAC values at the two measurement wavelengths were determined from the linear fits between $b_{\text {abs }}$ and EC mass, which yielded $\mathrm{MAC}_{532}=7.5 \pm 0.3 \mathrm{~m}^{2} \mathrm{~g}^{-1}\left(R^{2}=0.97\right)$ and $\operatorname{MAC}_{870}=5.2 \pm 0.9 \mathrm{~m}^{2} \mathrm{~g}^{-1}\left(R^{2}=0.94\right)$. As shown in Fig. 5, the MAC values appear to be independent of the thrust level and fuel type. The $\mathrm{MAC}_{870}$ is in good agreement with the filter-based determined MAC value by Petzold and Schröder (1998) for jet engine aerosol $\left(\mathrm{MAC}_{800}=\right.$ $6 \mathrm{~m}^{2} \mathrm{~g}^{-1}$ ), which, using the inverse wavelength dependency of the cross section, leads to $\mathrm{MAC}_{870 \text {, calc }}=5.5 \mathrm{~m}^{2} \mathrm{~g}^{-1}$. Our results are also in line with the MAC value of freshly generated light absorbing carbon proposed by Bond and Bergstrom (2007) $\left(\mathrm{MAC}_{550}=7.5 \pm 1.2 \mathrm{~m}^{2} \mathrm{~g}^{-1}\right)$, which, converted to the wavelengths of interest, results in $\mathrm{MAC}_{532, \mathrm{calc}}=7.8 \pm 1.2 \mathrm{~m}^{2} \mathrm{~g}^{-1}$ and $\mathrm{MAC}_{870, \text { calc }}=4.7 \pm$ $0.8 \mathrm{~m}^{2} \mathrm{~g}^{-1}$.

The MSC values were calculated using its relation with the SSA and MAC reported in Eq. (3). In contrast to the MAC, the SSA, and consequently the MSC, were found to be highly thrust-dependent. Using the SSA measured at $60 \%$ thrust $\left(\mathrm{SSA}_{532}=0.37 \pm 0.03 ; \mathrm{SSA}_{870}=0.09 \pm 0.01\right)$ and the MAC values reported above, this calculation yielded $\mathrm{MSC}_{532}=$ $4.5 \pm 0.4 \mathrm{~m}^{2} \mathrm{~g}^{-1}$ and $\mathrm{MSC}_{870}=0.54 \pm 0.04 \mathrm{~m}^{2} \mathrm{~g}^{-1}$. The MSC $_{532}$ falls within the higher end of MSCs measured for fresh biomass smoke by Levin et al. (2010). However, a more detailed comparison with literature values is hindered by the strong dependency of MSC on the particles size, morphology and chemical composition.

The wavelength-dependent MAC and MSC were determined by fitting the measurements with Eqs. (5) and (6), as shown in Fig. S14. The AAE in Eq. (5) was set to $1.0 \pm 0.2$, as inferred for the $\mathrm{BC}$ emissions at cruise thrust level $(60 \%)$ from the aethalometer measurements described in the Supplement Sect. S1.5. This is a widely accepted value of the AAE, often used in litera- 
(a)
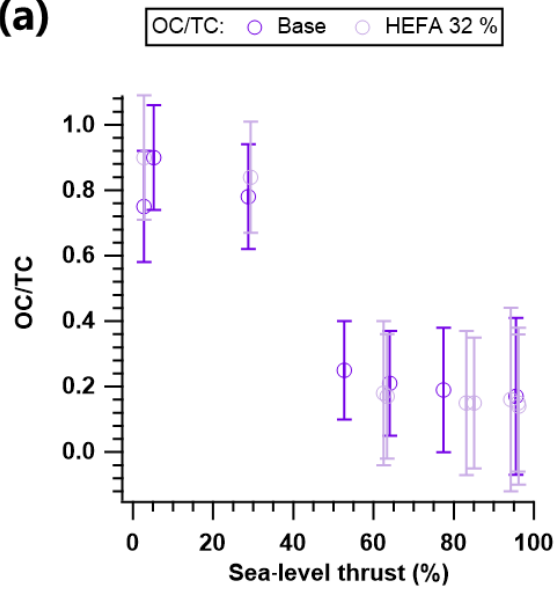

(b)

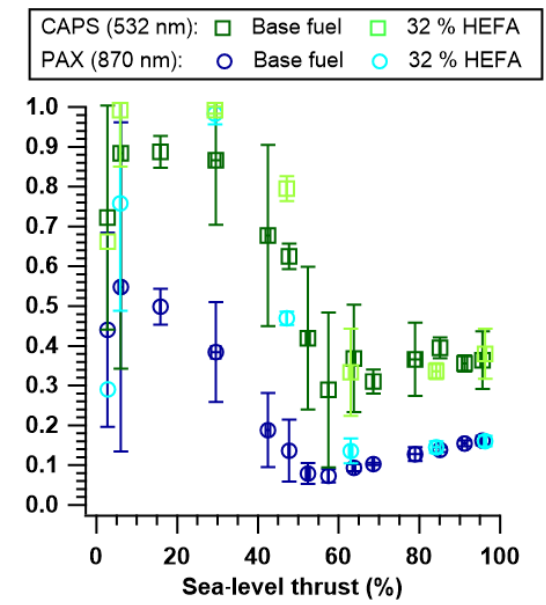

Figure 6. Thrust-dependent (a) organic carbon to total carbon fraction (OC/TC) and (b) single scattering albedo (SSA) measured at $532 \mathrm{~nm}$ (green squares) and $870 \mathrm{~nm}$ (blue circles). Note that dark colours represent measurements with base fuel (Jet A-1), and light colours represent measurements with the HEFA blend ( $32 \%$ vol).

ture for fresh $\mathrm{BC}$ particles. Lastly, $\mathrm{SAE}=4.5 \pm 0.7$ was calculated for cruise conditions using the scattering coefficients at the two measurement wavelengths, i.e. SAE $=$

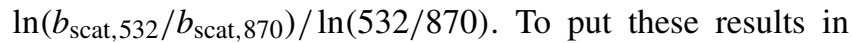
context, the obtained MAC and MSC spectra were used to estimate the direct radiative effect of fresh aircraft exhaust PM emissions during cruise, using the SFE defined in Eq. (4). A detailed description of the SFE model and its results can be found in the Supplement Sect. S2.4; in the following we briefly discuss the main findings. For high surface albedo surfaces like snow, aircraft fresh PM emissions induced a strong warming effect (integrated $\mathrm{SFE}_{450-2000, \text { snow }}=$ $4700 \mathrm{~W} \mathrm{~g}^{-1}$ ). Other land surfaces, such as soil and grass, resulted in a more moderate warming $\left(\mathrm{SFE}_{450-2000 \text {, soil }}=\right.$ $1500 \mathrm{~W} \mathrm{~g}^{-1} \mathrm{SFE}_{450-2000 \text {, grass }}=800 \mathrm{~W} \mathrm{~g}^{-1}$ ), while the effect of emissions over dark surfaces such as seawater was very low and had an overall cooling effect $\left(\mathrm{SFE}_{450-2000 \text {, sea }}=\right.$ $-90 \mathrm{~W} \mathrm{~g}^{-1}$ ). However, these results need to be taken with caution, as this simple radiative model does not consider the effect of underlying clouds. Moreover, we only consider the effect of fresh PM emissions, corresponding to an approximate time after emission of less than $0.6 \mathrm{~s}$, when the jet is still conserved, and high temperatures prevent the condensation of volatile species. Previous studies have shown that sulfuric acid plays an important role in the formation of secondary PM in near-field aircraft plumes (Kärcher et al., 1996). Thus, plume evolution measurements of the particles' optical properties (if possible in-flight) and more complex models are needed to assess the overall radiative effects of aircraft PM emissions.

\section{Conclusions}

This work presents the link between the EC/OC content and the optical properties of PM emissions at the engine exit plane of a CFM56-7B operated at a full range of thrust levels from ground idle to take-off. In addition, we examined the effects of using HEFA biofuel blends on the PM emissions and determined the main radiative properties of the fresh PM emissions, which are of great value for the modelling of their radiative effects.

The EC and OC mass concentrations, as well as the absorption and scattering coefficients, increased with thrust level. While PM at the engine exit plane is thought to mostly contain strongly absorbing EC, we found a significant fraction of OC at low thrust levels, which was linked to the high scattering and SSA values. In line with previous studies, the $32 \%$ vol HEFA blend significantly lowered the PM mass emissions, especially at low thrust levels, where the EC mass was reduced by $50 \%-60 \%$. The OC mass also decreased at most thrust levels, except at $3 \%$ thrust, where it seemed to be enhanced. However, at this thrust level we only had one sample for each fuel type, and the uncertainties attributed to these low thrust measurements with low concentrations were large.

The trends in the OC/TC ratio and the SSA highlighted important differences in the particles formed in the combustion process at different thrust levels. At low thrust levels, representative of ground idle and taxi, the particles were highly scattering $\left(\mathrm{SSA}_{532}=0.7-0.9\right)$ and contained large fractions of $\mathrm{OC}(\mathrm{OC} / \mathrm{TC}=0.75-0.9)$. In contrast, at the higher thrust levels, representative of cruise (60\% thrust) and take-off ( $100 \%$ thrust), the particles were mostly composed of highly absorbing EC $\left(\mathrm{SSA}_{532}=0.3-0.4\right.$ and $\mathrm{OC} / \mathrm{TC}=$ $0.2)$. The high OC fractions observed at low thrust levels are most probably a consequence of the lower efficiency of the 
combustion at these low engine powers. Regarding the use of HEFA blends, we could not see any significant effect of the different fuel types on the SSA and the OC/TC ratio.

The measurements of absorption and scattering at two different wavelengths, in combination with the measurements of EC mass, allowed us to evaluate the MAC and MSC and to study their wavelength dependence. Together with the SSA, the MAC and MSC are key parameters for the study of the PM radiative effects. The obtained MAC was found to be independent of the thrust level and matched the values reported in literature for fresh BC very well. In contrast, the MSC (and SSA) varied greatly with thrust level, as it strongly depends on particle size, morphology and composition. As for the SSA, no effect was observed on the MAC and MSC as a result of the use of the HEFA blends. Thus, the particles originated from the combustion of both fuel types seem to be equivalent in terms of their normalized optical properties, and only their concentrations change. Previous works found significant differences in the morphology of the particles emitted when burning pure alternative fuels compared to standard jet fuels, which would translate into major differences in the particles' optical properties (Huang and Vander Wal, 2013; Huang et al., 2016). However, this does not seem to be the case for blends of alternative fuels at practical ratios for widespread usage in the foreseeable future and with considerable $(>8 \% v / v)$ total aromatics content. In fact, Huang and Vander Wal (2013) found similar trends in the soot nanostructure evolution with thrust for standard jet fuel and its 50:50 blend with an alternative fuel, while the two pure biofuels tested produced distinct and varied types of nanostructures independent of the engine thrust. Huang and Vander Wal (2013) related these differences to the different degrees of turbulent mixing in the combustion chamber prior to soot formation, which is linked to the aromatic content in the fuel. Thus, soot formation from blends with up to $50 \%$ of alternative fuel is fairly similar to the one of the unblended base fuel, which results in emissions of soot particles with similar morphology, OC/TC ratios and intensive optical properties.

The wavelength-dependent MAC and MSC were used to estimate the instantaneous direct radiative forcing of fresh aircraft PM emissions during cruise conditions using a simple two-stream model. Our results showed that in the absence of clouds, when the emissions occurred over dark surfaces like seawater, the forcing efficiency was very small and had a net cooling effect. In contrast, these particles had a strong warming effect when emitted above highly reflective surfaces, such as snow or ice. However, more accurate and complex climate models that simulate the atmospheric ageing of the particles in the emission plume and take into account the effect of variable underlying cloud fields are required for a complete understanding of the impact of aviation particle emissions on the Earth's radiative balance.
Data availability. The numerical data used to make the figures in this paper and the corresponding Supplement are available at https://doi.org/10.5281/zenodo.2649204 (Elser et al., 2019).

Supplement. The supplement related to this article is available online at: https://doi.org/10.5194/acp-19-6809-2019-supplement.

Author contributions. ME designed the study and performed the laboratory calibrations and the data analysis. BTB and FS were in charge of fuel logistics. FS coordinated the test cell availability and engine lease. ME, BTB, LD and DS performed the jet engine measurements. AF performed the EC/OC analysis. ME wrote the paper, with important contributions from BTB, LD and AF. BTB, LD, AF and JW revised the paper.

Competing interests. The authors declare that they have no conflict of interest.

Acknowledgements. We thank Mike Weiner and the test cell crew from SR Technics AG for operating the engine testing facility, our EMPA colleagues Regula Haag and Daniel Rentsch for the fuel hydrogen analysis, Michael Arndt from AVL GmbH for loaning the PAX instrument and the group of André Prévôt from PSI for providing the aethalometer data.

Financial support. This research has been supported by the Swiss Federal Office of Civil Aviation (FOCA) (grant no. SFLV 2015113).

Review statement. This paper was edited by Paul Zieger and reviewed by three anonymous referees.

\section{References}

Arunachalam, S., Wang, B., Davis, N., Baek, B. H., and Levy, J. I.: Effect of chemistry transport model scale and resolution on population exposure to $\mathrm{PM}_{2.5}$ from aircraft emissions during landing and takeoff, Atmos. Environ., 45, 3294-3300, https://doi.org/10.1016/j.atmosenv.2011.03.029, 2011.

ASTM D7566-17a: Standard specification for aviation turbine fuel containing synthesized hydrocarbons, ASTM International, West Conshohocken, PA, 2017.

Balkanski, Y., Myhre, G., Gauss, M., Rädel, G., Highwood, E. J., and Shine, K. P.: Direct radiative effect of aerosols emitted by transport: from road, shipping and aviation, Atmos. Chem. Phys., 10, 4477-4489, https://doi.org/10.5194/acp-104477-2010, 2010.

Barrett, S. R. H., Britter, R. E., and Waitz, I. A.: Impact of aircraft plume dynamics on airport local air quality, Atmos. Environ., 74, 247-258, https://doi.org/10.1016/j.atmosenv.2013.03.061, 2013. 
Beyersdorf, A. J., Timko, M. T., Ziemba, L. D., Bulzan, D., Corporan, E., Herndon, S. C., Howard, R., Miake-Lye, R., Thornhill, K. L., Winstead, E., Wey, C., Yu, Z., and Anderson, B. E.: Reductions in aircraft particulate emissions due to the use of Fischer-Tropsch fuels, Atmos. Chem. Phys., 14, 11-23, https://doi.org/10.5194/acp-14-11-2014, 2014.

Birch, M. E. and Cary, R. A.: Elemental carbon-based method for monitoring occupational exposures to particulate diesel exhaust, Aerosol Sci. Tech., 25, 221-241, https://doi.org/10.1080/02786829608965393, 1996.

Bond, T. C. and Bergstrom R. W.: Light absorption by carbonaceous particles: An investigative review, Aerosol Sci. Tech., 40, 27-67, https://doi.org/10.1080/02786820500421521, 2007.

Brem, B. T., Durdina, L., Siegerist, F., Beyerle, P., Bruderer, K., Rindlisbacher, T., Rocci-Denis, S., Gurhan Andac, M., Zelina, J., Penanhoat, O., and Wang, J.: Effects of fuel aromatic content on nonvolatile particulate emissions of an in-production aircraft gas turbine, Environ. Sci. Technol., 49, 13149-13157, https://doi.org/10.1021/acs.est.5b04167, 2015.

Carslaw, D. C., Beevers, S. D., Ropkins, K., and Bell, M. K.: Detecting and quantifying aircraft and other on-airport contributions to ambient nitrogen oxides in the vicinity of a large international airport, Atmos. Environ., 40, 5424-5434, https://doi.org/10.1016/j.atmosenv.2006.04.062, 2006.

Chylek, P. and Wong, J.: Effect of absorbing aerosols on global radiation budget, Geophys. Res. Lett., 22, 929-931, https://doi.org/10.1029/95GL00800, 1995.

Delhaye, D., Ouf, F. X., Ferry, D., Ortega, I. K., Penanhoat, O., Peillon, S., Salm, F., Vancassel, X., Focsa, C., Irimiea, C., Harivel, N., Perez, B., Quinton, E., Yon, J., and Gaffie, D.: The MERMOSE project: Characterization of particulate matter emissions of a commercial aircraft engine, J. Aerosol Sci., 105, 48-63, https://doi.org/10.1016/j.jaerosci.2016.11.018, 2017.

Durdina, L., Brem, B. T., Setyan, A., Siegerist, F., Rindlisbacher, T., and Wang, J.: Assessment of Particle Pollution from Jetliners: from Smoke Visibility to Nanoparticle Counting, Environ. Sci. Technol., 51, 3534-3541, https://doi.org/10.1021/acs.est.6b05801, 2017.

Elser, M., Brem, B. T., Durdina, L., Schönenberger, D., Siegerist, F., Fischer, A., and Wang, J.: Zenodo, Empairex 1: Optical properties data archive, https://doi.org/10.5281/zenodo.2649204, 2019.

Hadaller, O. J. and Johnson, J. M.: World Fuel Sampling Program, CRC Report 647, Coordinating Research Council, Inc., Alpharetta, GA, 2006.

Hand, J. L. and Malm, W. C.: Review of aerosol mass scattering efficiencies from ground-based meaurements since 1990, J. Geophys. Res., 112, D16203, https://doi.org/10.1029/2007JD008484, 2007.

Haywood, J. M. and Shine, K. P.: Multi-spectral calculations of the direct radiative forcing of tropospheric sulphate and soot aerosols using a column model, Q. J. Roy. Meteor. Soc., 123, 1907-1930, https://doi.org/10.1002/qj.49712354307, 1997.

He, C., Liou, K.-N., Takano, Y., Zhang, R., Levy Zamora, M., Yang, P., Li, Q., and Leung, L. R.: Variation of the radiative properties during black carbon aging: theoretical and experimental intercomparison, Atmos. Chem. Phys., 15, 11967-11980, https://doi.org/10.5194/acp-15-11967-2015, 2015.

Hendricks, J., Kärcher, B., Döpelheuer, A., Feichter, J., Lohmann, U., and Baumgardner, D.: Simulating the global atmo- spheric black carbon cycle: a revisit to the contribution of aircraft emissions, Atmos. Chem. Phys., 4, 2521-2541, https://doi.org/10.5194/acp-4-2521-2004, 2004.

Howard, R., Hiers, R. S., Whitefield, P. D., Hagen, D. E., Wormhoudt, J. C., Miake-Lye, R. C., and Strange, R.: Experimental characterization of gas turbine emissions at simulated altitude conditions, Arnold Engineering Development Center, AEDC-TR-96-3, 1996.

Hsu, S., Fruin, S., Kozawa, K., Mara, S., Winer, A. M., and Paulson, S. E.: Aircraft emission impacts in a neighborhood adjacent to a general aviation airport in Southern California, Environ. Sci Technol., 43, 8039-8045, https://doi.org/10.1021/es900975f, 2009.

Huang, C.-H. and Vander Wal, R.L.,: Effect of soot structure evolution from commercial jet engine burning petroleum based JP-8 and synthetic HRJ and FT fuels, Energy Fuels, 27, 4946-4958, https://doi.org/10.1021/ef400576c, 2013.

Huang, C. H., Bryg, V. M., and Vander Wal, R. L.: A survey of jet aircraft PM by TEM in APEX III, Atmos. Environ., 140, 614 622, https://doi.org/10.1016/j.atmosenv.2016.06.017, 2016.

ICAO: Annex 16 to the Convention on International Civil Aviation, Environmental Protection, Volume II Aircraft Engine Emissions, 4th Edn., 2017.

Jacobson, M. Z., Wilkerson, J. T., Naiman, A. D., and Lele, S. K.: The effects of aircraft on climate and pollution. Part II: 20year impacts of exhaust from all commercial aircraft worldwide treated individually at the subgrid scale, Faraday Discuss., 165, 369-382, https://doi.org/10.1039/C3FD00034F, 2013.

Karagulian, F., Van Dingenen, R., Belis, C.A., Janssens Maenhout, G., Crippa, M., Guizzardi, D., and Dentener, F.: Attribution of anthropogenic $\mathrm{PM}_{2.5}$ to emission sources, JRC Technical Reports, EUR 28510 EN, https://doi.org/10.2760/344371, 2017.

Kärcher, B., Hirschberg, M. M., and Fabian, P.: Smallscale chemical evolution of aircraft exhaust species at cruising altitudes, J. Geophys. Res., 101, 15169-15190, https://doi.org/10.1029/96JD01059, 1996.

Khalizov, A. F., Xue, H., Wang, L., Zheng, J., and Zhang, R.: Enhanced light absorption and scattering by carbon soot aerosol internally mixed with sulfuric acid, J. Phys. Chem. A., 113, 10661074, https://doi.org/10.1021/jp807531n, 2009.

Kirchstetter, T. W., Corrigan, C. E., and Novakov, T.: Laboratory and field investigation of the adsorption of gaseous organic compounds onto quartz, Atmos. Environ., 35, 1663-1671, https://doi.org/10.1016/S1352-2310(00)00448-9, 2001.

Leahy, J.: Airbus Global Market Forecast 2016-2035, 2016.

Lee, H., Olsen, S. C., Wuebbles, D. J., and Youn, D.: Impacts of aircraft emissions on the air quality near the ground, Atmos. Chem. Phys., 13, 5505-5522, https://doi.org/10.5194/acp13-5505-2013, 2013.

Levin, E. J. T., McMeeking, G. R., Carrico, C. M., Mack, L. E., Kreidenweis, S. M., Wold, C. E., Moosmüller, H., Arnott, W. P., Hao, W. M., Collett Jr., J. L., and Malm, W. C.: Biomass burning smoke aerosol properties measured during Fire Laboratory at Missoula Experiments (FLAME), J. Geophys. Res., 115, D18210, https://doi.org/10.1029/2009JD013601, 2010.

Liati, A., Brem B. T., Durdina, L., Vögtli, M., Dasilva, Y. A. R., Eggenschwiler, P. D., and Wang, J.: Electron microscopic study of soot particulate matter emissions from air- 
craft turbine engines, Environ. Sci. Technol., 48, 10975-10983, https://doi.org/10.1021/es501809b, 2014.

Liu, S., Aiken, A. C., Arata, C., Dubey, M. K., Stockwell, C. E., Yokelson, R. J., Stone, E. A., Jayarathne, T., Robinson, A. L., DeMott, P. J., and Kreidenweis, S. M: Aerosol single scattering albedo dependence on biomass combustion efficiency: Laboratory and field studies, Geophys. Res. Lett., 41, 742-748, https://doi.org/10.1002/2013GL058392, 2014.

Lobo, P., Condevaux, J., Yu, Z., Kuhlmann, J., Hagen, D. E., Miake-Lye, R. C., Whitefield, P. D., and Raper, D. W.: Demonstration of a Regulatory Method for Aircraft Engine Nonvolatile PM Emissions Measurements with Conventional and Isoparaffinic Kerosene fuels, Energy Fuels, 30, 7770-7777, https://doi.org/10.1021/acs.energyfuels.6b01581, 2016.

Moore, R. H., Shook, M., Beyersdorf, A., Corr, C., Herndon, S., Knighton, W. B., Miake-Lye, R., Thornhill, K. L., Winstead, E. L., Yu, Z., Ziemba, L. D., and Anderson, B. E.: Influence of Jet Fuel Composition on Aircraft Engine Emissions: A Synthesis of Aerosol Emissions Data from the NASA APEX, AAFEX, and ACCESS Missions, Energy Fuels, 29, 2591-2600, https://doi.org/10.1021/ef502618w, 2015.

Moore, R. H., Thornhill, K. L., Weinzierl, B., Sauer, D., D’Ascoli, E., Kim, J., Lichtenstern, M., Scheibe, M., Beaton, B., Beyersdorf, A. J., Barrick, J., Bulzan, D., Corr, C. A., Crosbie, E., Jurkat, T., Martin, R., Riddick, D., Shook, M., Slover, G., Voigt, C., White, R., Winstead, E., Yasky, R., Ziemba, L. D., Brown, A., Schlager, H., and Anderson, B. E.: Biofuel blending reduces particle emissions from aircraft engines at cruise conditions, Nature, 543, 411-415, https://doi.org/10.1038/nature21420, 2017.

Onasch, T., Massoli, P., Kebabian, P., Hills, F., Bacon, F., and Freedman, A.: Single scattering albedo monitor for airborne particulates, Aerosol Sci. Tech., 49, 267-279, https://doi.org/10.1080/02786826.2015.1022248, 2015.

Parent, P., Laffon, C., Marhaba, I., Ferry, D., Regier, T. Z., Ortega, I. K., Chazallon, B., Carpentier, Y., and Focsa, C.: Nanoscale characterization of aircraft soot: A high-resolution transmission electron microscopy, Raman spectroscopy, X-ray photoelectron and near-edge X-ray absorption spectroscopy study, Carbon, 101, 86-100, https://doi.org/10.1016/j.carbon.2016.01.040, 2016.

Penner, J. E., Lister, D. H., Griggs, D. J., Dokken, D. J., and McFarland, M.: Aviation and the global atmosphere. A special report of IPCC working groups I and III, Intergovernmental Panel on Climate Change, 1999.

Petzold, A. and Schröder, F. P.: Jet Engine Exhaust Aerosol Characterization, Aerosol Sci. Tech., 28, 62-76, https://doi.org/10.1080/02786829808965512, 1998.
Reid, J. S., Eck, T. F., Christopher, S. A., Koppmann, R., Dubovik, O., Eleuterio, D. P., Holben, B. N., Reid, E. A., and Zhang, J.: A review of biomass burning emissions part III: intensive optical properties of biomass burning particles, Atmos. Chem. Phys., 5, 827-849, https://doi.org/10.5194/acp-5-827-2005, 2005.

Samset, B. H. and Myhre, G.: Vertical dependence of black carbon, sulphate and biomass burning aerosol radiative forcing, Geophys. Res. Lett., 38, L24802, https://doi.org/10.1029/2011GL049697, 2011.

Samset, B. H., Myhre, G., Schulz, M., Balkanski, Y., Bauer, S., Berntsen, T. K., Bian, H., Bellouin, N., Diehl, T., Easter, R. C., Ghan, S. J., Iversen, T., Kinne, S., Kirkevåg, A., Lamarque, J.-F., Lin, G., Liu, X., Penner, J. E., Seland, Ø., Skeie, R. B., Stier, P., Takemura, T., Tsigaridis, K., and Zhang, K.: Black carbon vertical profiles strongly affect its radiative forcing uncertainty, Atmos. Chem. Phys., 13, 2423-2434, https://doi.org/10.5194/acp13-2423-2013, 2013.

Schripp, T., Anderson, B., Crosbie, E. C., Moore, R. H., Herrmann, F., Oßwald, P., Wahl, C., Kapernaum, M., Köhler, M., Le Clercq, P., Rauch, B., Eichler, P., Mikoviny, T., and Wisthaler, A.: Impact of Alternative Jet Fuels on Engine Exhaust Composition During the 2015 ECLIF Ground-Based Measurements Campaign, Environ. Sci. Technol., 52, 4969-4978, https://doi.org/10.1021/acs.est.7b06244, 2018.

Schürmann, G., Schäfer, K., Jahn, C., Hoffmann, H., Bauerfeind, M., Fleuti, E., and Rappenglück, B.: The impact of $\mathrm{NO}_{\mathrm{x}}, \mathrm{CO}$ and VOC emissions on the air quality of the airport Zurich, Atmos. Environ., 41, 103-118, https://doi.org/10.1016/j.atmosenv.2006.07.030, 2007.

Strawa, A., Kirchstetter, T. W., Hallar, A. G., Ban-Weiss, G. A., McLaughlin, J. R., Harley, R. A., and Lunden, M. M.: Optical and physical properties of primary on-road vehicle particle emissions and their implications for climate change, J. Aerosol Sci., 41, 36-50, https://doi.org/10.1016/j.jaerosci.2009.08.010, 2010.

Subramanian, R., Khlystov, A. Y., Cabada, J. C., and Robinson, A. L.: Positive and negative artifacts in particulate organic carbon measurements with denuded and undenuded sampler configurations, Aerosol Sci. Tech., 38, 27-48, https://doi.org/10.1080/02786820390229354, 2004.

Vander Wal, R. L., Bryg, V. M., and Huang, C.-H.: Chemistry characterization of jet aircraft engine particulate matter by XPS: Results from APEX III, Atmos. Environ., 140, 623-629, https://doi.org/10.1016/j.atmosenv.2016.05.039, 2016.

Zarzycki, C. M. and Bond, T. C.: How much can the vertical distribution of black carbon affect its global direct radiative forcing?, Geophys. Res. Lett., 37, L20807, https://doi.org/10.1029/2010GL044555, 2010. 